\title{
Contribution to the Characterization of Palm Kernel Shell from Littoral, Cameroon
}

\author{
Dieunedort Ndapeu ${ }^{1,2^{*}}$, Jean Bosco Kuate Yagueka1,2, Efeze Dydimus Nkemaja ${ }^{3}$, \\ Bernard Morino Ganou Koungang3, Médard Fogue ${ }^{1,2}$, Ebenezer Njeugna ${ }^{3}$
}

\author{
${ }^{1}$ Research Unit of Industrial and Systems Engineering Environment (UR-ISIE), IUT/FV Bandjoun, University of Dschang, \\ Dschang, Cameroon \\ ${ }^{2}$ Research Unit of Mechanics and Modeling of Physical System (UR-2MSP), University of Dschang, Dschang, Cameroon \\ ${ }^{3}$ Laboratory of Mechanics and Adapted Materials (LAMMA), ENSET, University of Douala, Douala, Cameroon \\ Email: *ndapeu@yahoo.fr
}

How to cite this paper: Ndapeu, D., Yagueka, J.B.K., Nkemaja, E.D., Koungang, B.M.G., Fogue, M. and Njeugna, E. (2020) Contribution to the Characterization of Palm Kernel Shell from Littoral, Cameroon. Materials Sciences and Applications, 11, 668-677.

https://doi.org/10.4236/msa.2020.1110045

Received: August 16, 2020

Accepted: October 16, 2020

Published: October 19, 2020

Copyright (c) 2020 by author(s) and Scientific Research Publishing Inc. This work is licensed under the Creative Commons Attribution International License (CC BY 4.0).

http://creativecommons.org/licenses/by/4.0/

\begin{abstract}
The experimental study carried out in this work contributes to the physico-mechanical characterization of the palm kernel shells (PKS) Elaeis guineensis of the DURA and TENERA varieties. The knowledge of these properties gives an idea of their behaviour in the realization of composites and others. The absolute density was determined by the method of pycnometer, the porosity and compactness of PKS too; respectively $1428.81 \mathrm{~kg} / \mathrm{m}^{3}$ for Dura, $1395.81 \mathrm{~kg} / \mathrm{m}^{3}$ for Tenera; 0.041 for Dura, 0.158 for Tenera; 0.958 for Dura, 0.841 for Tenera. The impact energy of PKS by the pendulum sheep method has an average value of $2.066 \mathrm{~J} / \mathrm{cm}^{2}$ and $1.894 \mathrm{~J} / \mathrm{cm}^{2}$ for Dura and Tenera respectively at a temperature of $26^{\circ} \mathrm{C}$. The longitudinal Young's modulus of 19 $\mathrm{GPa}$ and 17.9 GPa for Dura and Tenera, respectively, was determined by applying the Castigliano theorem through a three-point bending test device.
\end{abstract}

\section{Keywords}

PKS, Density, Compactness, Impact Energy, Young's Modulus

\section{Introduction}

Oil palm, cultivated in more than twenty countries around the world, plays an important role in the peasant economy so far as this crop contributes firstly, to satisfy the domestic needs of farmers and secondly, to provide them with monetary income. Through our investigations, we have found that once the palm nut is separated from the shell, the latter is no longer used for anything or is sometimes used as a fuel for cooking, electricity production and decoration of art ob- 
jects $[1]$.

The annual world production of palm kernel shell amounts to about 21,359,000 tons, about 270,000 tons for Cameroon [2] [3]. In Cameroon, about $70 \%$ of these shells are dumped in the wild, causing pollution [1]. Because these plant by-products degrade very slowly.

Research work has been conducted on palm kernel shell, including the determination of physical-chemical properties [4] [5] [6]. The physical properties of PKS are essential parameters in the development of process methods and equipment design [7]. These properties include rheological, thermal, optical, electrical and some mechanical parameters. Palm kernel shells are also used in the production of activated carbon for water filtration and other applications [8]. Given their importance to the world economy in general and to Cameroon's economy in particular, palm kernel shell deserves more attention in order to optimize their potential. Further work has been or is being done on PKS. As a background application of palm kernel shell, we can mention their utilisation as fillers in the realization of brake pads, safety helmet. Also, in some localities in Cameroon, such as the Haut-Nkam, West region, palm kernel shells are dumped on muddy country roads in order to facilitate the adherence of car tyres [1], in addition, composite materials have been made from these shell and although their mechanical characteristics are poorly known, they have demonstrated many qualities, including their machinability and toughness [9].

In order to improve knowledge of the characteristics of PKS, this work aims to contribute to the physico-mechanical characterization of palm kernel shell.

\section{Materials}

Palm kernel shells used in this study come from a mature cob walnut from the production area of Nkongsamba for the DURA species and BOMONO for the TENERA species, all located in the Littoral Cameroon. The shells are extracted by drying the nuts. These shells are carefully cleaned before use to get rid of oil and fibres residues and are kept at a temperature of $105^{\circ} \mathrm{C}$ in the oven for four hours before packaging.

\section{Methods}

\subsection{Density}

The determination of the density parameters of the materials indirectly provides an approximation of the quality of their constructive properties.

\subsubsection{Absolute Density}

The absolute density is determined experimentally by the pycnometer method according to NF P 94-054. The procedure used consisted in carrying out the following operations:

- Select a sample and place it in the oven at $105^{\circ} \mathrm{C}$ for 24 hours.

- Weigh a pycnometer filled with distilled water to the mark and note its mass $M_{1}$. 
- Weighing a sample of aggregate of mass $M_{2}$.

- Introduce the sample into a pycnometer after pouring in a quantity of water.

- Gradually fill the pycnometer up to the mark, eliminate air bubbles and note $M_{3}$ its mass.

- Note the temperature of the water in the pycnometer.

The values of the individual weights are used to determine the absolute density.

$$
\rho_{a b s}=\rho_{e} \cdot M_{2} /\left[\left(M_{1}+M_{2}\right)-M_{3}\right]
$$

where $\rho_{e}$ is water density taken conventionally

\subsubsection{Apparent Density}

The bulk density was determined by the hydrostatic balance method according to the recommendations of NF P 94-053. The principle of the method consists in determining the volume of a sample by means of the Archimede thrust. It is obtained from successive weighing of the sample. Samples are taken by the quartage method and weighed on a $10^{-3}$ g precision scale.

- Let methe mass of the sample, then the sample is immersed in previously melted paraffin.

- Let $m_{e+p}$, the mass of the sample plus paraffin (with a density of 0.87796 $\mathrm{g} / \mathrm{cm}^{3}$ )

The wax sample is then carefully immersed in water.

o The displaced volume of water $V_{d}$ is given by the expression $V_{d}=V_{e}+V_{p}$

o The volume of the paraffin is: $V_{p}=\frac{m_{e+p}-m_{e}}{\rho_{p}}$

o The volume of the sample is given by the relationship $V_{e}=V_{d}-V_{P}$

The bulk density is expressed as the ratio of the mass of the sample to the volume of the sample.

$$
\rho_{a p}=\frac{m_{e}}{V_{e}}
$$

\subsection{Porosity $(p)$, Void Index $(e)$ and Compactness $(c)$}

The dimensionless characteristics, given by Equations (3), (4) and (5), provide information on the voids in a body.

$$
\begin{gathered}
e=\frac{\rho_{a b s}-\rho_{a}}{\rho_{a}} \\
p=\frac{e}{e+1} \\
c=1-P
\end{gathered}
$$

\subsection{Mechanical Characterization}

The mechanical characterization of palm kernel shell consists here of determining the longitudinal Young's modulus, the fish coefficient and the impact energy. The species of interest are DURA and TENERA. All palm kernel shells are 
obtained from mature nuts from the same cob for each species.

\subsubsection{Typology of Samples}

The palm kernel shell has geometry similar to that of the globe, i.e. it has two poles and meridians. To test the isotropy hypothesis, we propose to take samples in the Meridional direction and the Equatorial direction as shown in Figure 1.

We took the PKS DURA and TENERA specimens in the southern and equatorial directions. The aim was to see whether its mechanical characteristics vary according to the orientation in which the specimen was cut, in order to ensure the isotropy of this material. Table 1 represents the orientation $M$ and $E$ adopted; we have chosen a set of 20 specimens.

\subsubsection{Resilience Energy}

We determined it experimentally using the Charpy's Sheep method using a pendulum sheep adapted to plant shells, carried out at the LAMMA laboratory of ENSET, Douala as shown in Figure 2.

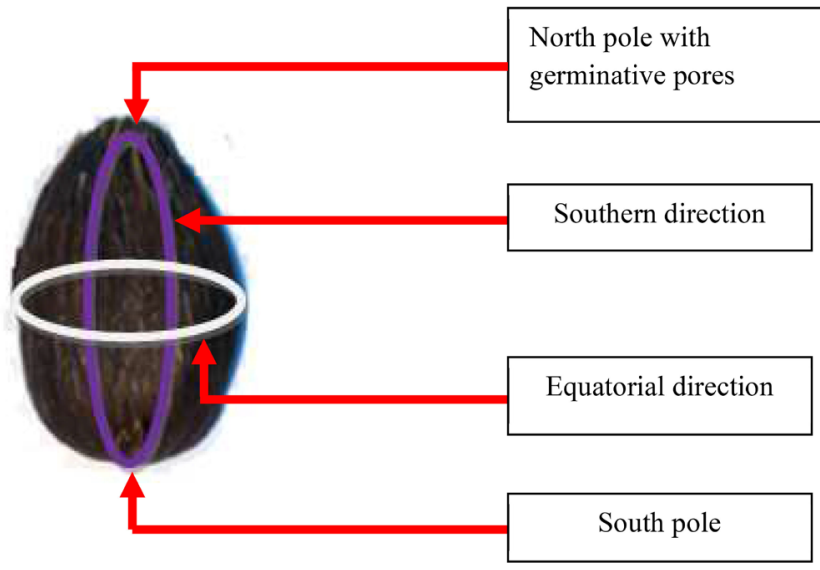

Figure 1. Image of palm nut.

Table 1. Adopted sample allocation terminology.

\begin{tabular}{cc}
\hline \multicolumn{1}{c}{ Designations } & Symbols \\
\hline Sample taken in the Southern direction & $M$ \\
Sample taken in the equatorial direction & $E$ \\
\hline
\end{tabular}
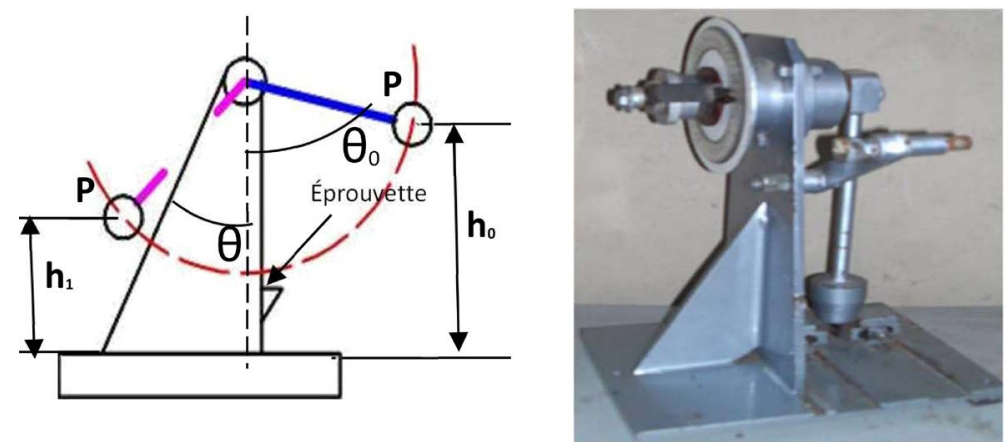

Figure 2. Schematic diagram of the pendulum sheep. 


$$
R=\frac{m g l\left(\cos \theta-\cos \theta_{0}\right)}{S}
$$

with 1 : length of the pendulum arm $(320 \mathrm{~mm})$;

$m$ : mass of the pendulum arm;

$\theta$. angle of ascent after specimen breakage;

$\theta_{0}$ : angle of free upward movement;

$g$ : acceleration of gravity at the test site;

$S$ : cross-section of the test specimen.

\section{Influence of temperature on impact energy}

This influence has been assessed by impact tests on specimens subjected to temperatures ranging from $26^{\circ} \mathrm{C}$ to $90^{\circ} \mathrm{C}$. For each temperature range, seven specimens were tested. The temperatures were measured using a type $\mathrm{K}$ thermocouple.

\subsubsection{Young's Modulus}

Due to the curved geometry, PKS does not offer the possibility to obtain straight specimens for the classical uniaxial tensile test; we will limit ourselves to three-point bending and elastic contact tests. The deformation energy will allow us to establish an equation whose parameters will be $E$ and $v$. We will take the fish coefficient value of 0.4 because palm kernel shells are similar to wood.

\section{1) Principle of the three-point bending test}

The bending test shall be carried out on a specimen in the form of a portion of a cylinder. This test piece is comparable to a curved beam whose mean line is in the form of an arc of a circle. We tested 20 specimens in the southern and equatorial directions. Figure 3 below shows the boundary conditions.

We place specimen (4) on the supporting surface integral with the frame (5), the end of the slide (2), bearing a steel ball is positioned at point $\mathrm{C}$ of the shell. The masses (1) are placed above a plate attached to the slide. The feeler of the dial gauge (3) is located under the shell and is used to directly measure the deflection corresponding to a given load in the extension of the slide rail. Several pairs of data (load, deflection) can be collected in the elastic range.

2) Mathematical expression of the deflection-load relationship

The application of Castigliano's theorem will allow us to establish a linear

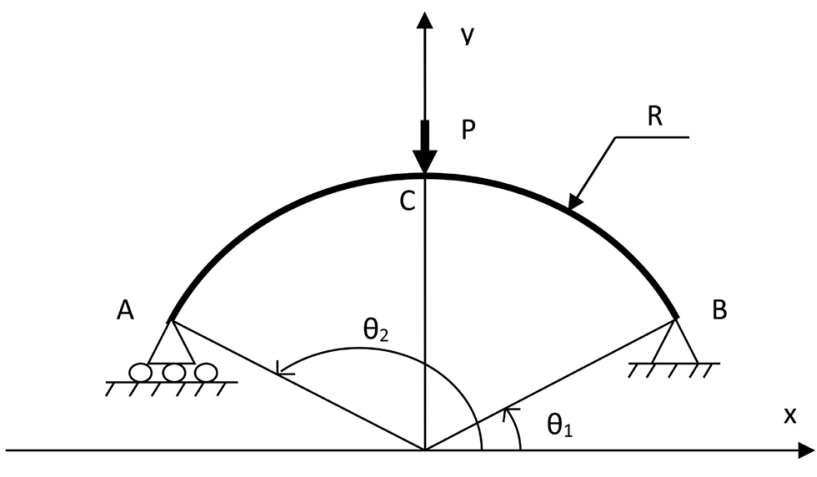

(a)

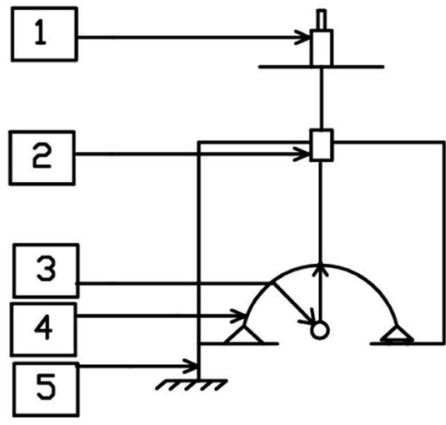

(b)

Legends:

1- Masses

2- Slider

3- Dial gauge

4- Sample

5- Frame

Figure 3. (a) Schematic diagram of the test (b) Three-point bending test apparatus. 
relationship $P=\alpha \cdot Y_{c}$ with $P$ the load applied at point $\mathrm{C}, Y_{c}$ the deflection at point $\mathrm{C}$ and $\alpha$ the slope of the straight line which is a function of the static Young's modulus, the fish coefficient and the geometric dimensions of the specimen.

3) Expression of the deformation energy of a specimen

The total deformation energy $U$ is due to internal forces [10] [11] [12] [13] is described by Equation (7) and given by Equation (8).

$$
U=2\left(U_{1}+U_{2}+U_{3}\right)
$$

with $U_{1}=$ Deformation energy due to normal effort $N$

$U_{2}=$ Deformation energy due to sharp effort $T_{R}$ is negligible

$U_{3}=$ Deformation energy due to flexural moment $M_{f z}$

$$
\begin{aligned}
U= & 2\left(U_{1}+U_{2}+U_{3}\right) \text { or } U_{2}=0 \Rightarrow \\
U= & 2\left\{\frac{R P^{2}}{16 E S}\left[\frac{\pi}{2}-\theta_{1}+\frac{1}{2} \sin \left(2 \theta_{1}\right)\right]+\frac{P^{2} R^{3}}{8 E I_{G z}}\left[\left(\frac{\pi}{2}-\theta_{1}\right) \cos ^{2} \theta_{1}\right.\right. \\
& \left.\left.-2 \cos \theta_{1}+\frac{3}{4} \sin 2 \theta_{1}+\frac{1}{2}\left(\frac{\pi}{2}-\theta_{1}\right)\right]\right\}
\end{aligned}
$$

$L$ and $e$ are the dimensions of the cross-section $S$.

$E$ is the static Young's modulus in longitudinal direction.

$P$ is the applied load.

$I_{G Z}=\frac{1}{12} \times L e^{3}$ is the quadratic moment of the straight section.

The application of Castigliano's theorem to the midpoint of the specimen C allows us to write $Y_{c}=\frac{\partial U}{\partial P}$ we thus obtain the relation below:

$$
\begin{gathered}
Y_{c}=\frac{\partial U}{\partial P} \\
\Rightarrow Y_{c}=\left\{\frac{R}{4 S}\left[\left(\frac{\pi}{2}-\theta_{1}\right)+\frac{1}{2} \sin 2 \theta_{1}\right]+\frac{R^{3}}{2 I_{G z}}\left[\left(\frac{\pi}{2}-\theta_{1}\right) \cos ^{2} \theta_{1}\right.\right. \\
\left.\left.-2 \cos \theta_{1}+\frac{3}{4} \sin 2 \theta_{1}+\frac{1}{2}\left(\frac{\pi}{2}-\theta_{1}\right)\right]\right\} \times \frac{P}{E}
\end{gathered}
$$

Let's pose

$$
\begin{aligned}
\beta= & \frac{R}{4 S}\left[\left(\frac{\pi}{2}-\theta_{1}\right)+\frac{1}{2} \sin 2 \theta_{1}\right] \\
& +\frac{R^{3}}{2 I_{G z}}\left[\left(\frac{\pi}{2}-\theta_{1}\right) \cos ^{2} \theta_{1}-2 \cos \theta_{1}+\frac{3}{4} \sin 2 \theta_{1}+\frac{1}{2}\left(\frac{\pi}{2}-\theta_{1}\right)\right]
\end{aligned}
$$

Substituting Equation (10) into Equation (9), gives Equation (11)

$$
Y_{c}=\beta \times \frac{P}{E}
$$

The factor $\beta$ depends on the geometrical characteristics of the specimens. From expression $\frac{P}{Y_{c}}=\frac{E}{\beta} ; E$ is determined. The slope $P / Y_{c}$ has been obtained experimentally as the slope of the linear regression. 


\section{Results and Discussions}

\subsection{Density of PKS}

The density of the palm kernel shell is given in Table 2 below.

This result shows that palm kernel shells of the species TENERA are more porous than those of the species DURA. This is not due to their parameters of cultivation or area of production. But fundamentally, this is attributable to their microstructure with and important porous network.

\subsection{Resilience Energy of PKS}

The average impact energy of palm kernel shell is $2.066 \mathrm{~J} / \mathrm{cm}^{2}$ and $1.894 \mathrm{~J} / \mathrm{cm}^{2}$ for DURA and TENERA species respectively at a temperature of $26^{\circ} \mathrm{C}$. It is clear that DURA PKS are more resistant to breakage. This resistance is directly linked to the highest density, compactness and low void index of Dura variety. Moreover, their structure and thickness are considerable. We also note that the resilience energy of the palm kernel shell decreases linearly with a correlation coefficient $\mathrm{R}^{2}$ of 0.914 with increasing temperature. It varies between $1.63 \mathrm{~J} / \mathrm{cm}^{2}$ at $50^{\circ} \mathrm{C}$ and $0.58 \mathrm{~J} / \mathrm{cm}^{2}$ at $90^{\circ} \mathrm{C}$ as shown in Figure 4 below.

\subsection{Young Modulus of PKS}

The Young's modulus of the palm kernel shell of the DURA variety is $19 \mathrm{GPa}$ and that of the TENERA variety is $17.9 \mathrm{GPa}$ at a temperature of $26^{\circ} \mathrm{C}$. Figure 5 below shows the variation in deflection as a function of load with a correlation coefficient $\mathrm{R}^{2}$ of 0.9956 .

In Table 3, we find that palm nut shells have a density close to that of coconut

Table 2. Void index, porosity, compactness and density values.

\begin{tabular}{ccc}
\hline SPECIES & DURA & TENERA \\
\hline Apparent density $\left(\mathrm{Kg} / \mathrm{m}^{3}\right)$ & 1370 & 1174 \\
Absolute density $\left(\mathrm{Kg} / \mathrm{m}^{3}\right)$ & 1428.81 & 1395.81 \\
Void index $(e)$ & 0.043 & 0.188 \\
Porosity $(p)$ & 0.041 & 0.158 \\
Compactness $(c)$ & 0.958 & 0.841 \\
\hline
\end{tabular}

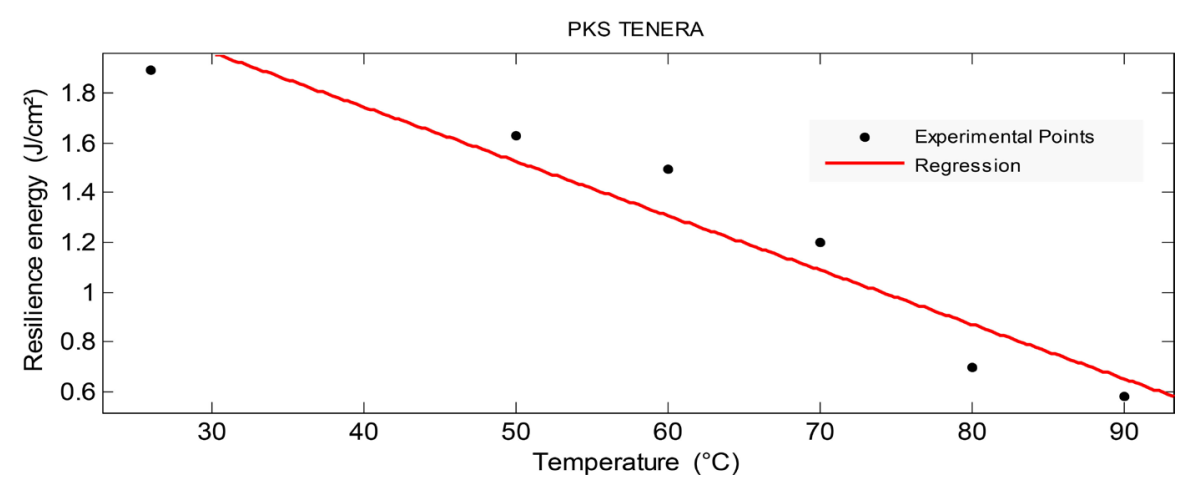

Figure 4. Impact enregy vs. temperature. 


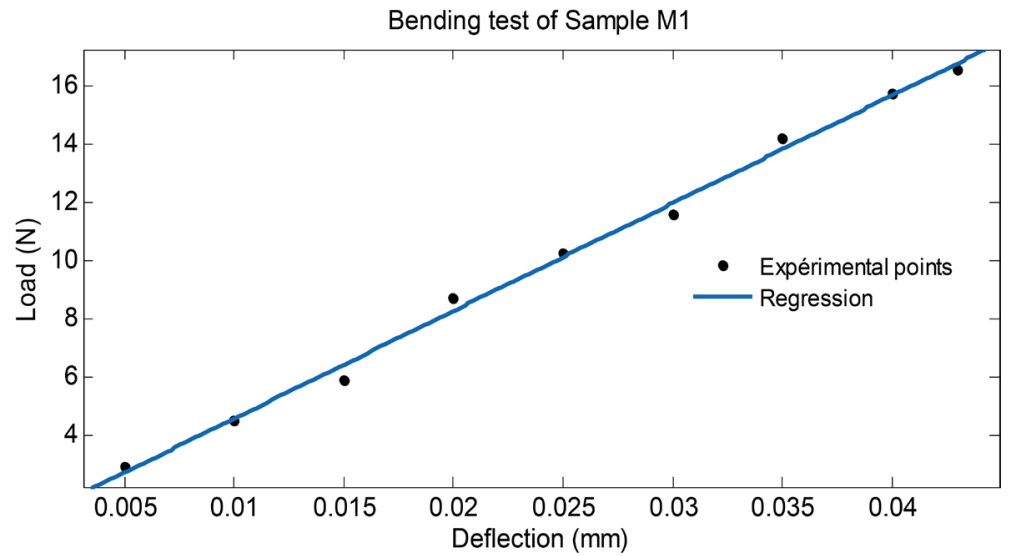

Figure 5. Variation of deflection with load.

Table 3. Comparison of absolute density and Young's modulus of some wood species.

\begin{tabular}{|c|c|c|c|}
\hline Wood species & Absolute Density $\left(\mathrm{Kg} / \mathrm{m}^{3}\right)$ & Young Modulus (Gpa) & References \\
\hline ACAJOU & $500-680$ & 9.5 & \\
\hline AFROMASIA & $650-800$ & 10.6 & \\
\hline AZOBE & $1000-1100$ & 17.3 & \\
\hline BILINGA & $730-890$ & 11.8 & \\
\hline BOSSE & $600-700$ & 10.8 & \\
\hline BIBINGA & $750-950$ & 16.3 & \\
\hline CELTIS & $620-900$ & 13.5 & \\
\hline DOUSSIE & $700-880$ & 13.7 & \\
\hline EBIARA & $600-800$ & 10.4 & \\
\hline EKABA(EKOP) & $500-750$ & 11.7 & \\
\hline GHEOMBI & $650-800$ & 15 & \\
\hline GOMBE & $570-690$ & 11.6 & \\
\hline IROKO & $550-750$ & 10.3 & \\
\hline KANDA & $700-760$ & 12.4 & \\
\hline KOSIPO & $600-780$ & 9 & \\
\hline LATI & $700-880$ & 13.2 & \\
\hline LIMBALI & $730-880$ & 14.5 & \\
\hline LONGHI & $700-800$ & 14.7 & \\
\hline MAKORE & $600-750$ & 11.2 & \\
\hline MANSONIA (BETE) & $600-700$ & 11 & \\
\hline MOABI & $800-900$ & 17 & \\
\hline SAPELLI & $600-780$ & 11.3 & \\
\hline Coconut shell & 1293 & 11.9 & [1] \\
\hline Palm kernel shell TENERA & 1395 & 17.9 & Present work \\
\hline Palm kernel shell DURA & 1428 & 19.03 & Present work \\
\hline
\end{tabular}


shells. The Young's modulus of the Tenera variety is close to that of AZOBE and MOABI that of the dura variety is higher than the majority of hardwood species available in Cameroon.

\section{Conclusions}

The physico-mechanical characteristics of the palm kernel shell of the DURA and TENERA varieties have been determined. The density of the palm kernel shells, by the Archimede thrust method, is $1428.81 \mathrm{~kg} / \mathrm{m}^{3}$ for Dura and 1395.81 $\mathrm{kg} / \mathrm{m}^{3}$ for Tenera respectively. Resilience energy was determined using a pendulum sheep at temperatures ranging from $26^{\circ} \mathrm{C}$ to $90^{\circ} \mathrm{C}$. It was found that the resilience energy decreases with increasing temperature. The deformation energy through the bending test was used to determine the longitudinal Young's modulus of the palm kernel shell. This differs from the specimens taken in the southern and equatorial direction of the shells as shown in Figure 1. It can therefore be seen that PKS are anisotropic materials.

The physico-mechanical parameters of PKS are essential for optimal use in structural and non-structural industrial applications, the development of process methods and even in equipment design. According to the results obtained, direct application can be the use as aggregate in concrete, fillers in composite material and others.

\section{Conflicts of Interest}

The authors declare no conflicts of interest regarding the publication of this paper.

\section{References}

[1] Njeugna, E., Ndapeu, D., Bistac, S., Drean, J.Y., Ngenefeme Foba, J. and Fogue, M. (2013) Contribution to the Characterization of the Coconut Shells (Coco Nucifera) of Cameroon. International Journal of Mechanics Structural, 4, 1-23.

[2] Gérard, J. and Edi Kouassi, A. (1998) Synthèse sur les caractéristiques technologiques de référence des principaux bois commerciaux africain. Série FORAFRI.

[3] GRET and GERES (1995) Transformation artisanale des plantes à huiles, expériences et procédés.

[4] Okoroigwe, E.C., Saffron, C. M. and Kamdem, P.D. (2014) Characterization of Palm Kernel Shell for Materials Reinforcement and Water Treatment. Journal of Chemical Engineering and Materials Science, 5, 1-6. http://dx.doi.org/10.5897/JCEMS2014.0172

[5] Koya, O.A., Idowu, A. and Faborode, M.O. (2004) Some Properties of Palm Kernel and Shell Relevant in Nut Cracking and Product Separation. Journal Agricultural Engineering and Technology, 12, 33-44.

[6] Ezeoha, S.L., Akubuo, C.O. and Ani, A.O. (2012) Proposed Average Values of Some Engineering Properties of Palm Kernels. Nigerian Journal of Technology (NIJOTECH), 31, 167-173.

[7] Epesse Misse, S., Obounou, M., Ayina Ohandja, L.M. and Caillat, S. (2013) Utilisation des coques de noix de palmiste comme combustible dans un four de fusion de la 
ferraille. Revue des Energies Renouvelables, 16, 75-89.

[8] Adewumi, I.K. (2009) Activated Carbon for Water Treatment in Nigeria: Problems and Prospects. In: Yanful, E.K., Ed., Appropriate Technologies for Environmental Protection in the Developing World, Springer, Dordrecht, 115-122.

https://doi.org/10.1007/978-1-4020-9139-1 13

[9] Ngarmkama, W., Sirisathitkulc, C. and Phalakornkule, C. (2011) Magnetic Composite Prepared from Palm Shell-Based Carbon and Application for Recovery of Residual Oil from POME. Journal of Environmental Management, 92, 472-479.

[10] Mukam Fotsing, J.A. (1990) Modélisation statistique du comportement mécanique du matériau bois, Application à quelques essences du Cameroun. Mémoire de Thèse, University of Douala, Cameroon.

[11] Delaplace, A., Gatuingt, F. and Ragueneau, F. (2008) Mécanique des structures. Dunod, Paris.

[12] Ramli, A. (2003) Short Term and Long-Term Projection of Malaysian Palm Oil Production. Oil Palm Industry Economic Journal, 3, 32-36.

[13] Bazergui, A., Thang Bui-quoc, D., Mcintyre, M. and Laberge, C. (1993) Résistance des matériaux 2ème édition de l'école polytechnique de Montréal. 